Sprachen und Dinge 
Anton Leist

\section{Sprachen und Dinge}

Der Gegenstandsbereich instrumentellen Handelns

J.B. Metzlersche Verlagsbuchhandlung Stuttgart 
CIP-Kurztitelaufnahme der Deutschen Bibliothek

Leist, Anton:

Sprachen und Dinge: d. Gegenstandsbereich instrumentellen Handelns / Anton Leist. Stuttgart: Metzler, 1979.

ISBN 978-3-476-00409-3

D 30

ISBN 978-3-476-00409-3

ISBN 978-3-476-03105-1 (eBook)

DOI 10.1007/978-3-476-03105-1

(c) Springer-Verlag GmbH Deutschland 1979

Ursprünglich erschienen bei J. B. Metzlersche Verlagsbuchhandlung und Carl Ernst Poeschel Verlag GmbH in Stuttgart 1979 


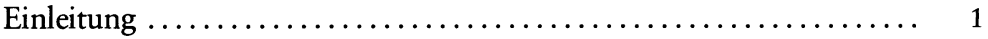

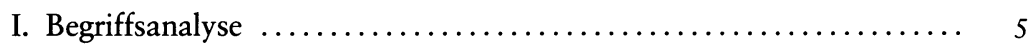

1. Idealismus vs. Realismus - eine sinnvolle Alternative? ............. 7

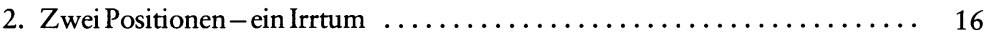

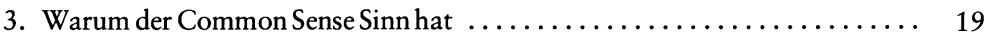

4. Carnaps Lösung: interne und externe Fragen $\ldots \ldots \ldots \ldots \ldots \ldots \ldots \ldots, 26$

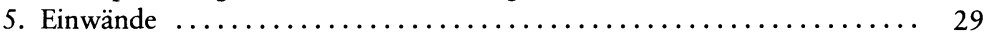

(a) Erkennen nur sprachlich? (b) Kein alternatives Begriffssystem möglich (c) Traditionelles Gepäck (d) Glauben und Meinen - ein unheilvoller Zirkel? (e) Cassandrarufe: Quines Warnung

II. Sprache im Funktionskreis instrumentellen Handelns . . . . . . . . . 45

1. Kommunikatives vs. instrumentelles Handeln $\ldots \ldots \ldots \ldots \ldots \ldots \ldots .45$

(a) Gegenstandsbereich (b) Dingsprache (c) Funktionskreis

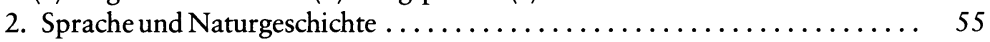

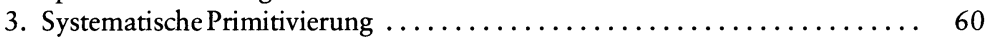

III. Dinge und Wahrnehmung $\left(L_{1}, L_{2}\right) \ldots \ldots \ldots \ldots \ldots \ldots \ldots \ldots \ldots \ldots$

1. Zwei primitive Sprachen $\left(L_{1}\right.$ und $\left.L_{2}\right)$ : Eigenschaften und Unterschiede . . . . 69

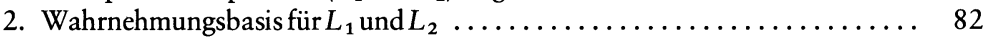

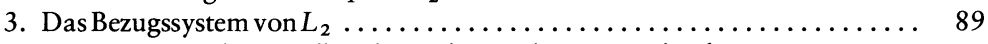

(a) Strawson und Tugendhat (b) Sind $L_{2}$ und $L_{3}$ trennscharf? (c) Die raumzeitlichen Gegenstände - das raumzeitliche System

4. Zur pragmatischen Erklärung von $L_{2} \ldots \ldots \ldots \ldots \ldots \ldots \ldots \ldots \ldots \ldots \ldots \ldots \ldots \ldots$

(a) Wozu $L_{2}$ zweckmäßig ist (b) Was $L_{2}$ voraussetzt

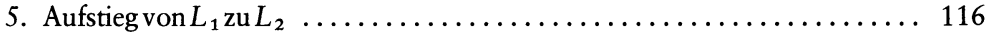

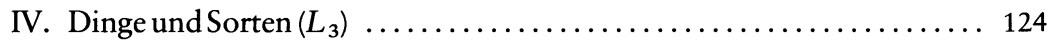

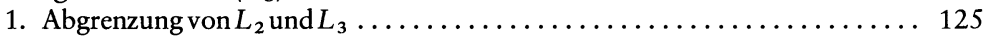

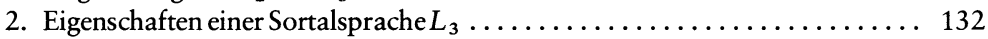

(a) Die Verwendungsweisen sortaler Ausdrücke (b) Das Sortalsystem

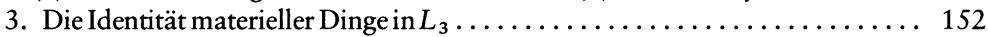

4. Zur pragmatischen Erklärung von $L_{3} \ldots \ldots \ldots \ldots \ldots \ldots \ldots \ldots \ldots \ldots \ldots \ldots \ldots$

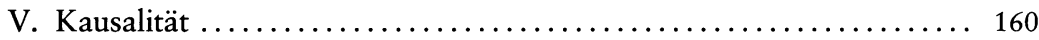

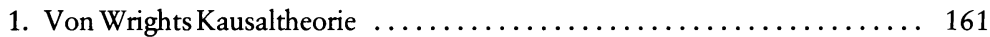

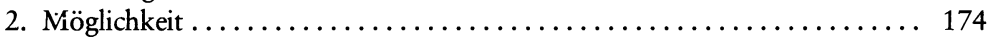

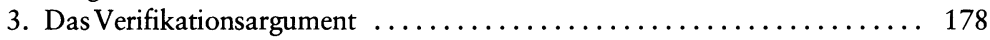

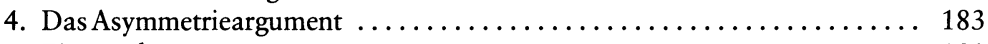

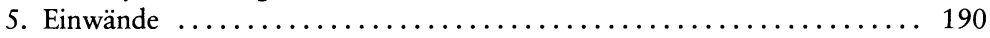

(a) Der Subjektivismusvorwurf (b) Der Zirkeleinwand (c) Das Abgrenzungsproblem: Kausalität/kausale Gesetze

VI. Materialien und instrumentelles Handeln $\left(L_{4}\right) \ldots \ldots \ldots \ldots \ldots \ldots \ldots 204$

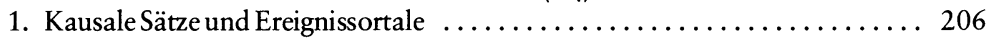

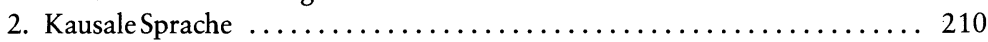

(a) Transitive Verben (b) Dispositionsprädikate 
Inhalt

3. Materialien ..................................... 218

(a) Materialien vs. Dinge (b) Materialien und Werkzeuge

VII. Bibliographie . 
Für Franziska Leist 